years, 36 were referred because of complaints from school: falling asleep in class, day dreaming, abrupt falling, and inattention. Attention deficit disorder was diagnosed in 10, hyperactivity in 12, epilepsy in 23, learning disability in 16 . Behavioral and learning problems prompted examination by school psychologists or counselors in 39 children before the correct diagnosis was established. Cataplexy (sudden loss of muscle tone) was precipitated by laughter, but was accompanied by fear of embarrassment and was often concealed from peers and adults. It was sometimes partial and caused only knee buckling, head and shoulder dropping, jaw sagging, and slurred speech. and was usually preceded by excessive daytime sleepiness. Sleep paralysis and hypnagogic hallucinations occurred in two thirds, at least once a week, and sometimes nightly. Polysomnograms showed sleep-onset REM sleep in 31. Multiple Sleep Latency Tests showed a mean sleep latency of $1.5 \mathrm{~min}+/-39$ secs; all children had 2 sleep-onset rapid eye movement sleep episodes in this test. HLA class II serotyping was positive for DQw6 in 46 children, and for DRw15 in 45. EEGs were "unremarkable," except for rapid onset of sleep. MRI in 14 and CT in 3 were normal. IQ mean score was $96+/-11$. Drug treatments included pemoline, methylphenidate, clomipramine, and fluoxetine; poor compliance was common, particularly after 7 years of age. Depressive reactions related to the illness, withdrawal from social interaction, poor selfesteem, and inadequate teacher understanding required psychological intervention. (Guilleminault C, Pelayo R. Narcolepsy in prepubertal children. Ann Neurol Jan 1998;43:135-142). (Respond: Dr Christian Guilleminault, Stanford Sleep Disorder Clinic, 401 Quarry Rd, Stanford, CA 94305).

COMMENT. Narcolepsy is uncommon during childhood, accounting for about $5 \%$ of cases attending a specialty clinic. The diagnosis is often delayed, and symptoms are mistaken for epilepsy, attention deficit disorder, learning and behavior problems. Early pharmacotherapy and counselling are recommended to prevent depressive reactions, school failures, and poor peer relationships. Delay in treatment results in irregular school attendance, academic failure, and poor self-esteem.

\title{
NOOGENIC SEIZURES
}

Self induced noogenic (thought provoked) absence seizures are reported in a photosensitive epileptic patient, a 20 year old man, treated at St Thomas' Hospital, London, UK. A febrile seizure at age 4 was followed by generalized tonic-clonic seizures precipitated by television at age 11 years and the onset of absence seizures at 12 years, coinciding with the time of his father's death. Photosensitivity to frequencies from 10 to $50 \mathrm{~Hz}$ were accompanied by $3-4 \mathrm{~Hz}$ polyspike and wave EEG discharges. Seizures were refractory to sodium valproate at age 15 , but were controlled by the addition of lamotrigine at age 18 and his introduction to university life. When seen at 20 years, he retrospectively admitted to having self induced seizures by thinking about his deceased father and the time he spent with him in the hospital. (Koutroumanidis M, Agathonikou A, Panayiotopoulos CP. Self induced noogenic seizures in a photosensitive patient. I Neurol Neurosurg \& Psychiatry Jan 1998;64:139-140). (Respond: Dr M Koutroumanidis, Department of Clinical Neurophysiology and Epilepsies, St Thomas' Hospital, Lambeth Palace Rd, London SE1 7EH, UK).

COMMENT. Reflex epilepsies can be precipitated by external stimuli, eg flickering lights or patterns, or by internal complex stimuli, eg thought processes. The latter are more difficult to diagnose, and are uncovered only by detailed history and patient admission. Emotional factors were obviously involved 
in the above patient's seizure disorder, and a change in life style was important in seizure control. Macdonald Critchley (1942) in his report of cases of musicogenic epilepsy considered emotion an important precipitant. (In Lennox WG. Epilepsy and Related Disorders. Boston, Little, Brown, 1960;p362). In his hagiographic obituary of Macdonald Critchley, who died Oct 15, 1997, aged 97, Robert J Joynt described him as "a reminder of the great heritage of our specialty and a vibrant contributor to it." (Arch Neurol Jan 1998;55:122).

\section{LORAZEPAM-INDUCED NEONATAL SEIZURES}

Two cases of lorazepam-induced neonatal seizures are reported from the University of Rochester, NY. Patient 1, a full-term male infant intubated for transient tachypnea was given lorazepam (Ativan), $0.1 \mathrm{mg} / \mathrm{kg}$ iv, for sedation. Within minutes, the infant developed clonic jerks of both legs and right arm, occurring in bursts of 1 to 3 min for 1 hour. A 24-hour EEG recorded 2 hours after movements resolved was normal. Patient 2 had necrotizing enterocolitis at 3 days of age and was treated briefly with antibiotics. A single dose of lorazepam, 0.1 $\mathrm{mg} / \mathrm{kg}$ iv, was given as a sedative for placement of a percutaneous intravenous catheter. Within $1 \mathrm{~min}$, intermittent clonic movements of all extremities were followed by flaccidity and pallor that lasted for $5 \mathrm{~min}$, and clonus recurred every 5 minutes for one half hour. Follow-up examinations at 12 months were normal in both infants. (Chess PR, D'Angio CT. Clonic movements following lorazepam administration in full-term infants. Arch Pediatr Adolesc Med Jan 1998;152:98-99). (Respond: Dr Patricia R Chess, Department of Pediatrics, University of Rochester, Rochester, NY 14642).

COMMENT. Myoclonus associated with lorazepam therapy in premature neonates is a well known side effect. This appears to be the first report of seizurelike activity following lorazepam injection in otherwise neurologically normal, full-term infants. Additional etiologic factors considered included the propylene glycol adjuvant in the injection and the rate of administration.

\section{VIGABATRIN-INDUCED VISUAL FIELD DEFECTS}

A drug surveillance database at Hoechst Marion Roussel, manufacturers of vigabatrin, identified 92 cases of symptomatic visual field defects associated with vigabatrin (usually as add-on therapy) between 1990 and 1997. Two further asymptomatic cases have been identified in patients treated at the Prince of Wales Hospital and University of Sydney, Australia. Patient 1, a 21-year-old man with complex partial seizures had received carbamazepine for 12 years and vigabatrin $2 \mathrm{~g} /$ day for three years. Clinical visual field testing was normal, but Goldman perimetry showed bilateral nasal field defects and some superior peripheral field constriction. Electroretinography was also abnormal, showing reduced $b$ wave amplitude. Patient 2, a 36-year-old woman with tonic-clonic seizures treated with valproate and carbamazepine for 12 years, followed by carbamazepine and vigabatrin $2 \mathrm{~g}$ /day for two years, had questionable defects on clinical visual field testing and definite peripheral binasal field loss on Humphrey perimetry. Electroretinography showed reduction in $\mathrm{b}$ wave amplitudes in nasal fields. (Mackenzie R, Klistorner A. Severe persistent visual field constriction associated with vigabatrin. Asymptomatic as well as symptomatic defects occur with vigabatrin. BMI Jan 17, 1998;316:232-233). (Respond: Dr Rod Mackenzie, Director, Comprehensive Epilepsy Service, Prince of Wales Hospital, Sydney, Australia).

COMMENT. Vigabatrin antiepileptic therapy poses the risk of visual field damage that may be persistent. The number of symptomatic cases identified could 